\title{
Comparison of adherence and persistence among multiple sclerosis patients treated with disease- modifying therapies: a retrospective administrative claims analysis
}

\author{
This article was published in the following Dove Press journal: \\ Patient Preference and Adherence \\ 20 January 2011 \\ Number of times this article has been viewed
}

\author{
Rachel Halpern' \\ Sonalee Agarwal ${ }^{2}$ \\ Carole Dembek ${ }^{2}$ \\ Leigh Borton' \\ Maria Lopez-Bresnahan ${ }^{3}$ \\ 'Health Economics and Outcomes \\ Research, i3 Innovus, Eden Prairie, \\ MN, USA; ${ }^{2}$ Health Outcomes and \\ Pharmacoeconomics, Biogen Idec, \\ Wellesley, MA, USA; ${ }^{3}$ Medical and \\ Scientific Affairs, i3 Research, \\ Waltham, MA, USA
}

Correspondence: Rachel Halpern I2125 Technology Drive, Eden Prairie, MN 55344, USA

$\mathrm{Tel}+\mathrm{I} 9528336280$

Fax + I 9528336045

Email rachel.halpern@i3innovus.com
Purpose: To compare adherence and persistence among patients with multiple sclerosis (MS) initiated on disease-modifying therapy (DMTs), including intramuscular (IM) interferon beta-1a (IFN $\beta-1 a$ ), subcutaneous (SC) IFN $\beta-1 a$, IFN $\beta-1 b$, or glatiramer acetate (GA).

Methods: MS patients initiated on IM-IFN $\beta-1 \mathrm{a}$, SC-IFN $\beta-1 \mathrm{a}$, IFN $\beta-1 \mathrm{~b}$, or GA between January 1, 2000 and January 2, 2008 were identified from a retrospective claims database study associated with a large US health plan. The date of DMT initiation was the index date; patients were observed for 6 months before and 12-36 months after the index date. Adherence to the index DMT was measured with a medication possession ratio (MPR), the proportion of days patients possessed their index DMTs; MPR $\geq 0.80$ was considered adherent. Persistence was time in days from index date until the earlier of a minimum 60-day gap in DMT therapy or the last DMT claim during follow-up. Adherence and persistence were modeled with logistic and Cox proportional hazard regressions, respectively.

Results: The study population comprised 6,680 patients in the DMT cohorts: IM-IFN $\beta-1 \mathrm{a}$ $(\mathrm{N}=2,305,34.5 \%)$; IFN $\beta-1 \mathrm{~b}(\mathrm{~N}=894,13.4 \%)$; GA $(\mathrm{N}=2,270,34.0 \%)$; and SC-IFN $\beta-1 \mathrm{a}$ $(\mathrm{N}=1,211,18.1 \%)$. The IM-IFN $\beta$-1a cohort had significantly higher regression-adjusted odds of adherence relative to the other cohorts: $52.4 \%$ higher odds versus the IFN $\beta$ - $1 \mathrm{~b}$ cohort $(\mathrm{OR}=0.656, \mathrm{CI}=0.561-0.768) ; 33.5 \%$ higher odds versus the GA cohort $(\mathrm{OR}=0.749$, $\mathrm{CI}=0.665-0.844)$; and $20.6 \%$ higher odds versus the SC-IFN $\beta-1$ a cohort $(\mathrm{OR}=0.829$, $\mathrm{CI}=0.719-0.957)$. There were no consistent differences in persistence between the cohorts.

Conclusion: IM-IFN $\beta$-1a patients had significantly higher odds of adherence compared with other DMT cohorts, possibly attributable to IM-IFN $\beta$-1a's less frequent dosing schedule. The benefits of adherence may include better quality of life, lower risk of relapse, and fewer hospitalizations and emergency visits, making adherence a critical component of MS management.

Keywords: multiple sclerosis, immunomodulatory therapy, patient compliance

\section{Introduction}

Multiple sclerosis (MS) is an incurable, chronic inflammatory disorder of the central nervous system ${ }^{1,2}$ that affects approximately 2.5 million people worldwide including about 400,000 individuals in the United States. ${ }^{3}$ Relapsing-remitting MS (RRMS) is the most common form of the disease and accounts for approximately $85 \%$ of MS diagnoses. ${ }^{4}$ RRMS is characterized by defined and acute attacks of worsening neurological function (relapses) that are followed by partial or complete recovery (remission). While the exact pathogenesis of MS is not known, it is thought to be an autoimmune disorder. Females are at greater risk of developing MS than are males. 
The risk of MS also increases with such factors as Caucasian race, family history of MS, and geographic origin. ${ }^{5}$ Initial onset of symptoms typically occurs between 20 and 40 years of age; diagnosis of MS after the age of 50 is rare. ${ }^{5}$

Treatment for MS focuses on disease management to prevent and treat relapses, manage symptoms, and slow disease progression. The introduction of immunomodulatory drugs, also referred to as disease-modifying therapy (DMT), in the early 1990 s changed the course of patient care. Two interferon- $\beta$ (IFN $\beta$ ) products are indicated to decrease relapse rates and slow disability progression: subcutaneous IFN $\beta$-1a (SC-IFN $\beta$-1a, Rebif $^{\circledR}$ ) administered three times per week and intramuscular IFN $\beta$-1a (IM-IFN $\beta$-1a, Avonex ${ }^{\circledR}$ ) administered once per week. Subcutaneous IFN $\beta$-1b (Betaseron ${ }^{\circledR}$, Extavia $^{\circledR}$ launched in 2009), administered every other day, and glatiramer acetate $\left(\mathrm{GA}\right.$, Copaxone $^{\circledR}$ ) administered subcutaneously daily are indicated only to decrease relapse rates. ${ }^{6-9}$ Although other DMTs have been approved for treatment of RRMS, including natalizamab (Tysabri ${ }^{\circledR}$, indicated for treatment after failure of first-line DMT therapy) and mitoxantrone $\left(\right.$ Novatrone $\left.^{\circledR}\right)$, interferons and GA are the predominant therapies prescribed upon diagnosis of MS or the decision to initiate treatment.

Poor adherence to medications prescribed for chronic conditions has been cited by the World Health Organization as a global problem that can lead to increased morbidity and mortality. ${ }^{10,11}$ Adherence is defined as the extent to which a patient acts in accordance with the prescribed timing, dosing, and frequency of medication administration. ${ }^{12}$ In MS research, studies have shown that patients who are adherent to DMTs have a lower risk of relapse than do patients who are non-adherent. ${ }^{13}$ Other MS studies have reported better quality of life for adherent patients compared with non-adherent patients. ${ }^{14,15}$ Adherence is measured in different ways, depending on the data source. In observational analyses of administrative claims data, adherence is measured frequently with a medication possession ratio (MPR) or proportion of days covered (PDC); these variables measure the proportion of time observed during which patients possess the therapy of interest. ${ }^{12,16}$ MPR or PDC values range from 0.0 to 1.0 with 1.0 indicating perfect adherence. Adherence may also be represented as the proportion of time during which patients do not have their medications (eg, cumulative gap ratio, continuous measure of medication gaps). ${ }^{16}$ In observational or prospective analyses of primary patient survey data, participants are commonly asked to recall the number of missed medication doses over a short period of time. ${ }^{14,15}$ Self-reported adherence, however, may be biased toward overestimation of adherence due to recall bias or a desire to please the practitioner or investigator. ${ }^{17,18}$

Observational studies that have collected patientreported data have shown that patient adherence to DMTs is suboptimal, a consistent and compelling finding given the limitations with self-reported adherence. Treadaway et al ${ }^{14}$ conducted a multicenter observational study in which MS patients treated with DMTs participated in an internet-based survey during 3 consecutive months. Patients were considered adherent if they did not miss any of their DMT injections in the 4 weeks prior to each survey. DMT adherence rates were $61 \%, 63 \%$, and $64 \%$, respectively, during the first, second, and third months. Devonshire and colleagues ${ }^{15}$ assessed DMT adherence in a multicenter observational study of over 2,600 patients with MS. Adherence in this study was defined as not missing a single dose in the 4 weeks prior to the survey and the authors reported an overall adherence rate of $75 \%{ }^{15}$ A recent prospective single-center study at the University of Kansas Medical Center assessed adherence over an 8-week period in 67 patients. ${ }^{19}$ Almost $80 \%$ of patients were treated with GA. The study found that only $40 \%$ of patients had perfect adherence (missed no dose of medication) during the 8 -week study period. ${ }^{19}$

Persistence is another measure of medication-taking behavior, defined as "the duration of time from initiation to discontinuation of therapy". ${ }^{12}$ Persistence studies using administrative claims data include a pre-specified limit on the maximum number of days, commonly 60 or 90 days, allowed between refills; this limit is referred to as the "permissible gap". ${ }^{2}$ A patient who exceeds the permissible gap between refilling prescriptions is considered non-persistent.

Several studies have assessed persistence and discontinuation of DMT. Tremlett and colleagues ${ }^{20}$ conducted a retrospective chart review of $844 \mathrm{MS}$ patients who were prescribed interferon-beta therapy from 1995 to 2001. Overall, 76 of the 844 (9\%) patients discontinued interferonbeta therapy within the first 6 months. Of the 203 patients who were followed for at least 3 years, $61 \%$ remained on therapy without interruption. DMT persistence also was assessed in a single center, prospective study of 632 patients with MS who initiated therapy on interferon-beta or GA from October 1995 through February 2004. ${ }^{21}$ The mean time of follow-up for the 622 patients included in the analysis was 47.1 months. During the entire study period, $17 \%$ of patients stopped DMT with almost half of those stopping during the first 2 years of therapy. Of the 266-patient cohort that was followed for at least 4 years, 212 or $80 \%$ remained on treatment with no interruption. $^{21}$ 
Limitations of the published literature on DMT adherence and persistence include small sample sizes, ${ }^{19,22}$ single-center studies, ${ }^{19,21}$ and geographically restricted populations. ${ }^{20,21}$ Moreover, many DMT persistency studies include only interferon therapy. ${ }^{20,22,23}$ Analysis with large administrative claims databases provides more comprehensive study populations, bigger study populations, and more generalizable results. The objective of this study was to use a large claims database from a national US health plan to compare adherence and persistence between patients initiated on interferons or GA and to expand findings of previous research.

\section{Methods Study design and data source}

This was a retrospective claims database study using medical and pharmacy data and enrollment information. The data included medical and pharmacy claims data and eligibility information from a large, national US health plan that provides fully insured coverage for professional, facility, and outpatient prescription pharmacy services. Medical (professional, facility) claims included International Classification of Diseases, 9th Revision, Clinical Modification (ICD-9-CM) diagnosis codes, ICD-9 procedure codes, Current Procedural Terminology, Version 4 (CPT-4) procedure codes, Healthcare Common Procedure Coding System (HCPCS) procedure codes, and site of service codes. Outpatient pharmacy claims provided National Drug Codes (NDC) for dispensed medications, quantity dispensed, drug strength, and number of days of supply (days supply). The individuals covered by this health plan, 26.9 million adults during the identification period of January 1, 2000 through January 2, 2008, were geographically diverse across the US, with greatest representation in the South and Midwest US census regions. All study data were accessed using techniques compliant with the Health Insurance Portability and Accountability Act of 1996, and no identifiable protected health information was extracted during the course of the study. Because this study involved analysis of pre-existing, de-identified data, it was exempt from Institutional Review Board approval.

\section{Patient selection}

The study population was selected from commercial health plan members initiating DMTs. All patients had at least one medical claim with a primary or secondary ICD-9-CM diagnosis code (340) for MS and at least one medical or pharmacy claim for IM-IFN $\beta$-1a, SC-IFN $\beta-1 \mathrm{a}$, IFN $\beta-1 \mathrm{~b}$, or GA during the identification period of January 1, 2000 through January 2, 2008. Patients taking IFN $\beta$-1b marketed as Extavia ${ }^{\circledR}$ were not included in this analysis as the drug was approved in 2009, after the inclusion dates for this study. The date of the first observed DMT claim was defined as the index date and that therapy was the index DMT. Patients were at least 18 years old during the year of index date. Patients with an index DMT claim with HCPCS code J1825 (assigned both to IM-IFN $\beta$-1a and SC-IFN $\beta$-1a until 2003) and with no subsequent claims that would allow distinct identification of IM-IFN $\beta$-1a or SC-IFN $\beta$-1a were excluded from the study population.

Patients were required to have continuous enrollment with medical and pharmacy benefits for 6 months before index date (baseline period) and at least 12 months follow-up, including the index date. The follow-up period was variable, up to a maximum of 36 months, in order to maximize sample size, and ended after the first 12 months with the earliest of: death, measured by patient disposition status from facility claims; health plan disenrollment; 3 years; or December 31, 2008. The entire observation period was July 1, 1999 (earliest start of baseline period) through December 31, 2008 (latest end of follow-up period). Patients had no medical or pharmacy claims for any DMT during the baseline period; the exclusion of patients with any DMT claims during their baseline periods was imposed to focus on new DMT users.

\section{Patient demographics and clinical characteristics}

Age, gender, and geographic region of health plan enrollment were captured from enrollment data. Baseline clinical characteristics included the Quan et $\mathrm{al}^{24}$ claims-based adaptation of the Charlson comorbidity index score ${ }^{24-26}$ and measures of MS severity. MS severity measures were binary indicators that identified patients with: at least one baseline MS-related emergency room (ER) visit; at least one baseline MS-related inpatient stay; and at least one baseline corticosteroid prescription fill or injection (injected corticotrophin or methylprednisolone, or oral dexamethasone, methylprednisolone, prednisolone, or prednisone). ${ }^{27}$ MS-related was defined as a medical claim from an ER visit or inpatient stay with a primary MS diagnosis.

\section{Adherence and persistence}

Adherence and persistence were measured during the follow-up period, including the index date. Adherence to index therapy was measured using MPR, calculated as: days supply of the index DMT divided by the days observed for the index DMT; days observed for the index DMT was number of days from the index date until the earlier of DMT 
switch or end of follow-up period. MPR was selected as the adherence measure because of its focus on medication possession (compared with such "non-possession" measures as cumulative gap ratio). MPR $\geq 0.80$ was considered adherent; ${ }^{16,28,29}$ MPR $<0.80$ was non-adherent. Persistence was measured as the number of days until the earlier of the last DMT claim before a minimum 60-day gap in therapy or the last DMT claim during the follow-up period. Patients whose last DMT claim was 60 days or fewer before the end of follow-up were considered persistent throughout the follow-up period. The distinction between days observed for the index DMT and persistence was that days observed for the index DMT were all days that patients should have been on their index DMTs, including days during gaps in therapy, while persistence measured only the time until the first "permissible gap" in therapy. ${ }^{12,16}$

\section{Analysis}

Variables were analyzed descriptively. Comparisons among the four cohorts were performed with analysis of variance with Bonferonni adjustment for continuous variables and with chi-square statistics for categorical variables. In addition, paired comparisons were made between patients on IM-IFN $\beta$-1a and each of the other index DMTs. A Bonferonni approximation was employed to adjust for the multiple paired comparisons. The adjusted $P$-value that indicated significance was 0.017 and was computed as ( $\alpha /$ number of comparisons), or $(0.05 / 3) .{ }^{30}$ Adherence (MPR $\geq 0.80$ ) was modeled with logistic regression. Persistence was modeled with Cox proportional hazard regression; the failure event was non-persistence any time during the follow-up period (ie, a minimum 60-day gap in therapy or the last observed DMT claim more than 60 days before the end of the follow-up period). Covariates were selected based on clinical importance or observed statistically significant differences in the descriptive analysis. They included: index DMT, age, gender, Charlson comorbidity index score, and indicators for baseline MS-related inpatient stay, baseline MS-related ER visits, and baseline corticosteroid utilization. Time observed for the index DMT, scaled to number of months (ie, days observed for the index DMT/30), was a covariate in the logistic regression to control for varying lengths of time on therapy.

Sensitivity analyses were conducted for each regression model. First, because SC-IFN $\beta$-1a became available in the US DMT market in April 2002, separate logistic and Cox proportional hazard regressions were estimated for patients with index dates (ie, who initiated DMT therapy) after April 2002; these regressions captured the population for whom IM-IFN $\beta$-1a, IFN $\beta$-1b, GA, and SC-IFN $\beta$-1a were available when they initiated therapy. Second, logistic regressions with different adherence thresholds (MPR $\geq 0.70)$ and (MPR $\geq 0.90)$ were estimated for the entire study population and for the subset of patients with index dates after April 2002. Third, the Cox proportional hazard regression was estimated using a 90-day therapy gap threshold for the entire study population and for the subset of patients with index dates after April 2002.

\section{Results}

The selection criteria yielded a study population of 6,680 patients distributed over the four DMT cohorts: IM-IFN $\beta$-1a $(\mathrm{N}=2,305,34.5 \%)$; IFN $\beta-1 \mathrm{~b}(\mathrm{~N}=894,13.4 \%)$; GA $(\mathrm{N}=2,270,34.0 \%)$; and SC-IFN $\beta$-1a $(\mathrm{N}=1,211,18.1 \%)$. Figure 1 depicts patient selection and attrition associated with each inclusion criterion.

\section{Unadjusted analysis results}

Table 1 provides the demographic and clinical characteristics of the DMT cohorts. There were few significant differences in age and gender, and significant differences in demographic characteristics were not clinically meaningful. The IM-IFN $\beta$-1a cohort was distributed differently across Charlson comorbidity index score compared with the SC-IFN $\beta$-1a cohort $(P=0.005)$. Lower proportions of the IM-IFN $\beta$-1a cohort relative to the IFN $\beta$-1b cohort had at least one MS-related ER visit (1.5\% versus 3.5\%, respectively, $P<0.001)$ or at least one MS-related inpatient stay (5.3\% versus $7.6 \%$, respectively, $P=0.013$ ) during the 6-month baseline period. Lower proportions of the IM-IFN $\beta$-1 a cohort compared with the SC-IFN $\beta$-1a cohort had at least one baseline MS-related inpatient stay $(5.3 \%$ versus $7.8 \%, P=0.003)$ and corticosteroid utilization $(34.7 \%$ versus $41.9 \%, P<0.001)$. The IM-IFN $\beta$-1a cohort had a mean (standard deviation) of 743 (322) days observed for the index therapy compared with the SC-IFN $\beta$-1a cohort (692 [319] days, $P<0.001$ ).

Unadjusted comparisons of MPR, persistence, gaps in therapy, and binary adherence are presented in Table 2. Patients in the IM-IFN $\beta$-1 a cohort had a mean MPR of 0.77 (ie, possessed their DMTs for $77 \%$ of the days observed for their index therapies, on average) compared with mean MPR of 0.70 in the IFN $\beta-1 b$ cohort $(P<0.001), 0.72$ in the GA cohort $(P<0.001)$, and 0.74 in the SC-IFN $\beta-1 \mathrm{a}$ cohort $(P=0.010)$. A higher proportion of the IM-IFN $\beta$-1a cohort $(62.3 \%)$ was adherent at MPR $\geq 0.80$ compared with the IFN $\beta$ - 1 b cohort $(52.2 \%, P<0.001)$ and the GA cohort $(55.4 \%, P<0.001)$. Patients treated with IM-IFN $\beta-1 \mathrm{a}$ 
Subjects with $\geq 1$ primary or secondary multiple sclerosis diagnosis and $\geq 1$ disease-modifying therapy (DMT) in identification period 1/1/2000-1/2/2008 ("original population")

$$
N=30,453
$$

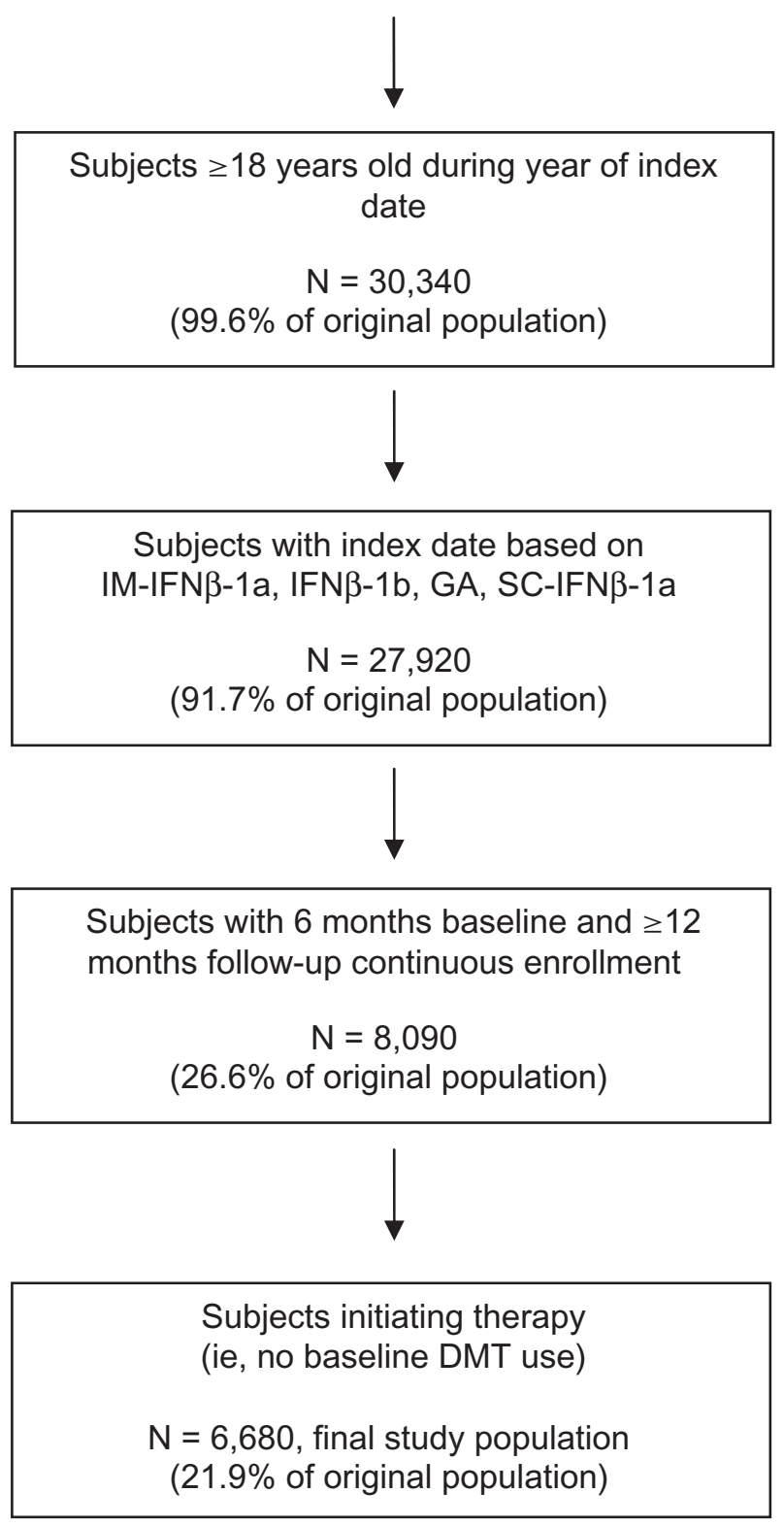

Figure I Subject selection and attrition.

were more persistent (508 [374] days) compared with those treated with GA (471 [373] days, $P=0.001$ ) and SC-IFN $\beta$-1a (471 [358] days, $P=0.005$ ).

\section{Regression results}

The results of the logistic regression modeling adherence at MPR $\geq 0.80$ for the entire study population are shown in Table 3; in addition, the regression-adjusted odds ratios (ORs) for the cohort indicators are exhibited in Figure 2. The ORs show that the IM-IFN $\beta$-1a cohort had significantly higher odds of adherence relative to the other cohorts: $52.4 \%$ higher odds of adherence relative to the IFN $\beta-1 \mathrm{~b}$ cohort $(\mathrm{OR}=0.656, \mathrm{CI}=0.561-0.768) ; 33.5 \%$ higher odds of adherence compared with the GA cohort $(\mathrm{OR}=0.749, \mathrm{CI}=0.665-0.844)$; and $20.6 \%$ higher odds of adherence versus the SC-IFN $\beta$-1a cohort $(\mathrm{OR}=0.829$, $\mathrm{CI}=0.719-0.957$ ). Males had significantly higher odds of adherence, as did patients with baseline corticosteroid use. Months observed for the index DMT was significantly and inversely associated with adherence, although the effect was small; the odds of adherence were $1 \%$ lower with each additional month patients were observed on their index DMTs.

Results from the Cox proportional hazard regression model of persistence estimated for the whole study population are displayed in Table 4. There were no significant differences in the likelihood of failing to achieve persistence (ie, in having a minimum 60-day gap in therapy) between the IM-IFN $\beta-1 \mathrm{a}$ cohort and the IFN $\beta-1 \mathrm{~b}$ or GA cohorts. Patients treated with SC-IFN $\beta$-1a were $11.7 \%$ more likely to be non-persistent compared with the IM-IFN $\beta$-1a cohort (hazard ratio $=1.117, \mathrm{CI}=1.013-1.233)$. Males were significantly less likely to be non-persistent and patients with Charlson comorbidity index scores $>2$ (relative to those with scores $=0$ ) were significantly more likely to be non-persistent. The test of proportional hazards based on Schoenfeld residuals revealed that the hazard ratio associated with SC-IFN $\beta-1$ a was not proportional throughout the follow-up period (rho $=-0.047$, chi-square $=7.18, P=0.007$ ); that is, the hazard ratio between the IM-IFN $\beta$-1a and SC-IFN $\beta-1$ a cohorts varied over the duration of the follow-up period. Figure 3 shows a Kaplan-Meier curve of non-persistence for the IM-IFN $\beta$ - $1 \mathrm{a}$ and SC-IFN $\beta-1 \mathrm{a}$ cohorts. Consistent with the test of proportional hazards, Figure 3 shows that although the rate of non-persistence was consistently higher for the SC-IFN $\beta$-1a cohort, the lines were not parallel throughout follow-up. Thus, the regression results indicate that the SC-IFN $\beta$-1a was, on average, more likely to have 60-day therapy gaps throughout the follow-up period. ${ }^{31}$

\section{Sensitivity analysis results}

When the logistic regression to model adherence was estimated on the subset of patients with index dates after April 2002 (when all 4 DMTs were available), the ORs for the IFN $\beta-1 \mathrm{~b}$ and GA cohorts were $0.636(\mathrm{CI}=0.529-0.766)$ and $0.768(\mathrm{CI}=0.670-0.880)$, respectively. The OR for the 


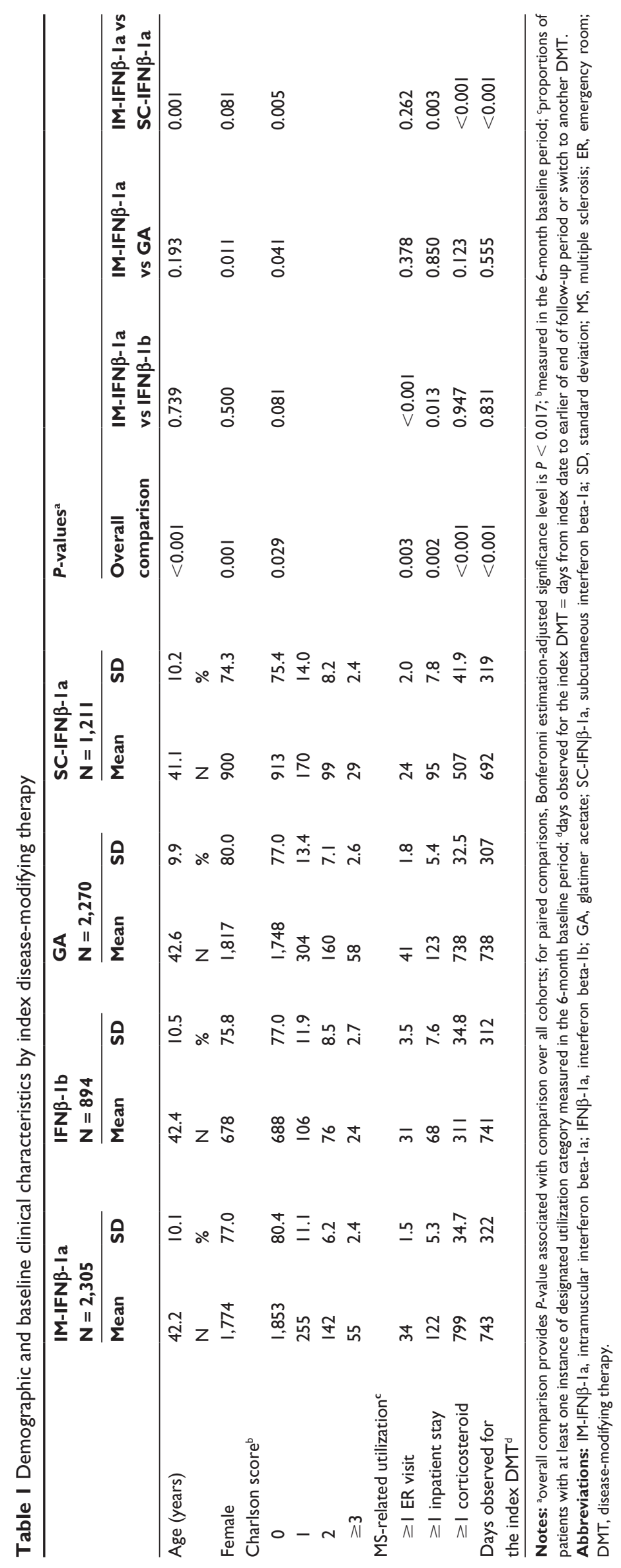




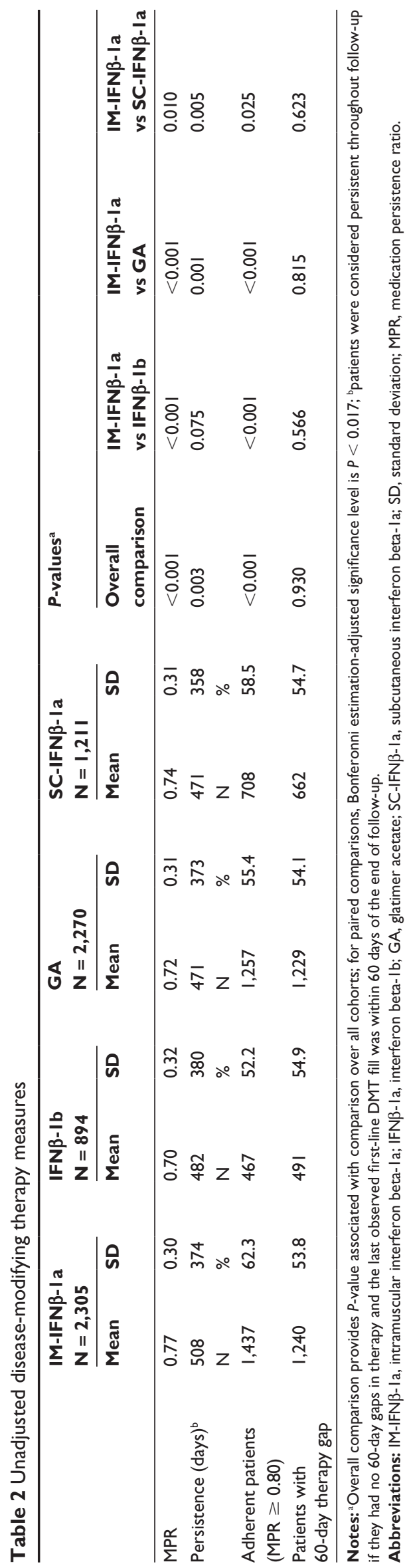

Table 3 Results of logistic regression modeling adherence: all patients

\begin{tabular}{|c|c|c|c|}
\hline & \multicolumn{3}{|c|}{ Adherence (MPR $\geq 0.80)$} \\
\hline & Odds ratio & $\begin{array}{l}95 \% \text { confidence } \\
\text { interval }\end{array}$ & $P$-value \\
\hline IFN $\beta$-Ib & 0.656 & $(0.56 \mathrm{I}-0.768)$ & $<0.001$ \\
\hline GA & 0.749 & $(0.665-0.844)$ & $<0.001$ \\
\hline SC-IFN $\beta-I a$ & 0.829 & $(0.719-0.957)$ & 0.011 \\
\hline Age & 1.011 & $(1.006-1.016)$ & $<0.001$ \\
\hline Male & 1.266 & $(1.125-1.426)$ & $<0.001$ \\
\hline $\begin{array}{l}\text { Charlson comorbidity } \\
\text { index score }=1\end{array}$ & 1.093 & $(0.939-1.273)$ & 0.250 \\
\hline $\begin{array}{l}\text { Charlson comorbidity } \\
\text { index score }=2\end{array}$ & I.08I & $(0.888-1.316)$ & 0.436 \\
\hline $\begin{array}{l}\text { Charlson comorbidity } \\
\text { index score }>2\end{array}$ & 0.790 & $(0.575-1.086)$ & 0.147 \\
\hline $\begin{array}{l}\text { Baseline MS-related } \\
\text { inpatient stay }\end{array}$ & 1.061 & $(0.853-1.319)$ & 0.595 \\
\hline $\begin{array}{l}\text { Baseline MS-related } \\
\text { ER visit }\end{array}$ & 0.757 & $(0.529-1.083)$ & 0.128 \\
\hline $\begin{array}{l}\text { Baseline } \\
\text { corticosteroid }\end{array}$ & 1.138 & $(\mathrm{I} .024-\mathrm{I} .265)$ & 0.016 \\
\hline $\begin{array}{l}\text { Time observed } \\
\text { for the index DMT } \\
\text { (months) }\end{array}$ & 0.990 & $(0.986-0.995)$ & $<0.001$ \\
\hline Observations & 6,680 & & \\
\hline
\end{tabular}

Notes: Reference disease-modifying therapy = IM-IFN $\beta$-Ia; reference Charlson comorbidity index score $=0$.

Abbreviations: IM-IFN $\beta$ - Ia, intramuscular interferon beta-Ia; IFN $\beta$ - Ia, interferon beta-Ib; GA, glatimer acetate; SC-IFN $\beta$-la, subcutaneous interferon beta-la; MS, multiple sclerosis; ER, emergency room; DMT, disease-modifying therapy.

SC-IFN $\beta$-1a cohort was $0.877(95 \% \mathrm{CI}=0.752-1.002)$ and not significant. The results of the primary regression, described above and shown in Table 3 and Figure 2, and the sensitivity analysis on the subset of patients with index dates after April 2002 remained consistent when 0.70 and 0.90 adherence thresholds were used as dependent variables. In the full-population models, the ORs for the IFN $\beta-1 b$, GA, and SC-IFN $\beta-1 \mathrm{a}$

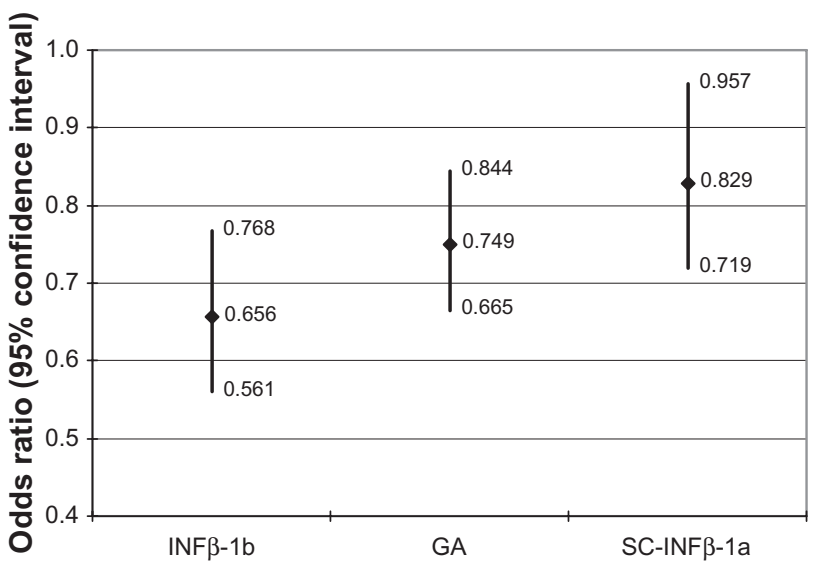

Figure 2 Regression-adjusted odds ratios of adherence compared with IM-IFN $\beta$ - Ia: all patients.

Abbreviation: IM-IFN $\beta$ - Ia, intramuscular interferon beta- Ia; IFN $\beta$ - Ia, interferon beta-Ib; GA, glatimer acetate; SC-IFN $\beta$-Ia, subcutaneous interferon beta-Ia. 
Table 4 Results of Cox proportional hazards regression modeling persistence: all patients

\begin{tabular}{|c|c|c|c|}
\hline & \multicolumn{3}{|c|}{ Persistence defined with 60-day gap } \\
\hline & Hazard ratio & $\begin{array}{l}95 \% \text { Confidence } \\
\text { interval }\end{array}$ & $P$-value \\
\hline IFN $\beta-I b$ & 1.020 & $(0.912-1.141)$ & 0.728 \\
\hline GA & 1.022 & $(0.939-1.112)$ & 0.612 \\
\hline SC-IFN $\beta$-Ia & 1.117 & $(1.013-1.233)$ & 0.027 \\
\hline Age & 0.985 & $(0.981-0.988)$ & $<0.001$ \\
\hline Male & 0.826 & $(0.759-0.899)$ & $<0.001$ \\
\hline $\begin{array}{l}\text { Charlson comorbidity } \\
\text { index score }=1\end{array}$ & 1.068 & $(0.961-1.188)$ & 0.221 \\
\hline $\begin{array}{l}\text { Charlson comorbidity } \\
\text { index score }=2\end{array}$ & 1.119 & $(0.979-1.279)$ & 0.098 \\
\hline $\begin{array}{l}\text { Charlson comorbidity } \\
\text { index score }>2\end{array}$ & 1.489 & $(1.208-1.835)$ & $<0.001$ \\
\hline $\begin{array}{l}\text { Baseline MS-related } \\
\text { inpatient stay }\end{array}$ & 0.920 & $(0.79|-| .07 \mid)$ & 0.282 \\
\hline $\begin{array}{l}\text { Baseline MS-related } \\
\text { ER visit }\end{array}$ & 1.149 & $(0.896-1.473)$ & 0.275 \\
\hline $\begin{array}{l}\text { Baseline } \\
\text { corticosteroid }\end{array}$ & 1.005 & $(0.934-1.082)$ & 0.884 \\
\hline Observations & 5,880 & & \\
\hline
\end{tabular}

Notes: Reference disease-modifying therapy = IM-IFN $\beta$-Ia; reference Charlson comorbidity index score $=0$.

Abbreviations: IM-IFN $\beta$-Ia, intramuscular interferon beta-la; IFN $\beta$-Ia, interferon beta-Ib; GA, glatiramer acetate; SC-IFN $\beta-1 \mathrm{a}$, subcutaneous interferon beta-la; MS, multiple sclerosis; ER, emergency room.

cohorts were below 1.0 and significant, indicating lower odds of adherence relative to the IM-IFN $\beta$-1a cohort. In the models for the subset of the population with index dates after April 2002, the ORs for the IFN $\beta-1 b$ and GA cohorts were below 1.0 and significant, and the OR for the SC-IFN $\beta$-1a cohort was not significant (data not shown).

For patients with index dates after April 2002, the persistence model results showed that the hazard ratios for

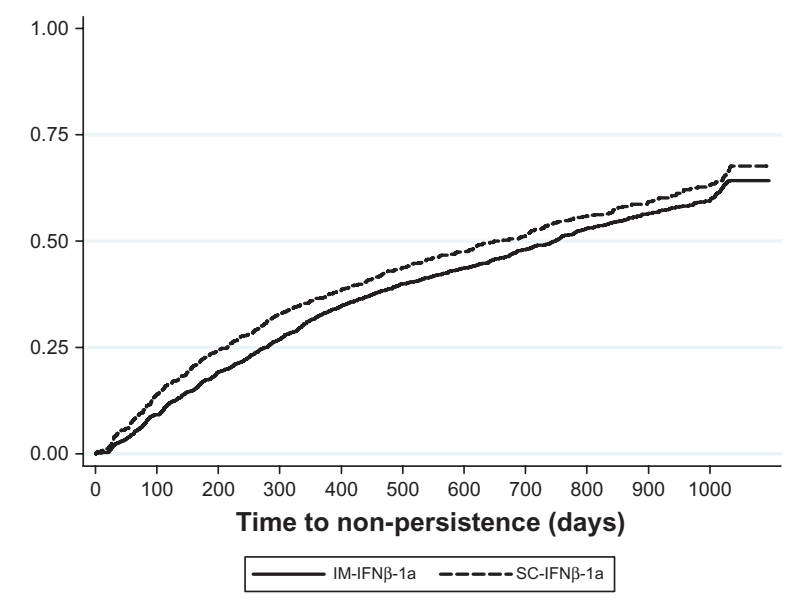

Figure 3 Kaplan-Meier failure curve of non-persistence.

Abbreviations: IM-IFN $\beta$-Ia, intramuscular interferon beta-Ia; SC-IFN $\beta$-Ia, subcutaneous interferon beta- Ia.
IFN $\beta$-1b, GA, and SC-IFN $\beta$-1a were all non-significant, at 1.049 (CI $=0.920-1.196), 1.018(\mathrm{CI}=0.924-1.121)$, and $1.068(\mathrm{CI}=0.962-1.187)$, respectively. The results shown in Table 4 remained consistent when the Cox proportional hazards regression was estimated for the entire study population using the 90-day therapy gap threshold. When the persistence regression with the 90-day therapy gap definition was applied to the subset of patients with index dates after April 2002, none of the DMT cohort hazard ratios were significant (data not shown).

\section{Discussion}

This study analyzed patients with MS who initiated treatment on IM-IFN $\beta$-1a, IFN $\beta$-1b, GA, and SC-IFN $\beta$-1a over an 8 -year period (1/1/2000-1/2/2008). Overall, patients treated with IM-IFN $\beta$-1a had significantly higher odds of adherence than did patients treated with other DMTs. The results of the persistence analysis showed that the IM-IFN $\beta$-1a cohort was more likely to be persistent (less likely to have a 60 - or 90-day gap in therapy) than was the SC-IFN $\beta$-1a cohort when the entire study population was analyzed, but not when the study population was limited to those who initiated treatment when all 4 DMTs were available; there were no significant differences in persistence between the IM-IFN $\beta$-1 a cohort and the GA or IFN $\beta-1 b$ cohorts in any persistence regression.

The combination of adherence (measured with MPR) and persistence provides a more comprehensive perspective on DMT utilization than does either measure individually. MPR shows the proportion of days that patients possessed their medications, but not the length of time that they used their medications continuously. For example, an MPR $=0.50$ indicates that patients possessed their medications for $50 \%$ of the days they were observed: the MPR value $=0.50$ could be achieved if patients were perfectly adherent for one half of their observation periods and perfectly non-adherent during the other half of their observation periods, or if patients had alternating 28-day periods with and without their medications. Persistence shows the duration that patients had their medications before a minimum gap in therapy. Persistence as typically measured, ${ }^{12}$ however, does not account for restarting a medication after a gap in therapy. For instance, patients with short lengths of persistence could have high levels of adherence if they restarted their medications and used them persistently after their first gaps in therapy.

For our study population, regression-adjusted results showed that patients in the IM-IFN $\beta$-1a cohort had significantly higher odds of adherence than did patients on other 
DMTs. This is important because MS is a chronic disease and patients need to take medication doses as required to achieve the optimal DMT efficacy. While we cannot observe patients' actual use of their DMTs, we infer that patients used their DMTs at the doses prescribed because adherence rates were relatively high (over 70\%) and the mean days on first-line DMTs were between 692 and 743 (Table 2); in other words, we assume that because patients acquired multiple fills of their index DMTs, they used the DMTs between fills. However, there were no significant (or consistently significant) differences in persistence across cohorts, although the IM-IFN $\beta$-1a cohort appeared to have a longer, unadjusted period of persistence. This suggests that even though patients in the IM-IFN $\beta$-1a cohort had higher odds of adherence, they did not refill their medications continuously. This combination of adherence and persistence findings indicates that patients treated with different DMTs were equally likely to persist on their DMTs, but that patients in the IM-IFN $\beta$-1a cohort tended to have fewer gaps in therapy, shorter gaps in therapy, or both over the duration of their follow-up periods.

Our findings are consistent with other studies that have reported higher adherence rates for patients on IM-IFN $\beta$-1a compared with patients on GA, IFNB-1b, or SC-IFN $\beta-1 a{ }^{14,15}$ Devonshire reported a significantly higher adherence rate for patients on IM-IFN $\beta$-1a compared with patients on SC-IFN $\beta-1 a$, GA, or IFN $\beta-1 b .{ }^{15}$ Similarly, Treadaway observed that patients on IM-IFN $\beta$ - 1 a had higher adherence rates than patients on SC-IFN $\beta-1 \mathrm{a}, \mathrm{GA}$, or IFN $\beta-1 b .{ }^{14}$ The IM-IFN $\beta$-1a cohort in the Reynolds et al study was significantly more adherent during the first 6 months of observation than were the GA, IFN $\beta$-1B, or SC-IFN $\beta$-1a cohorts. ${ }^{28}$ The IM-IFN $\beta$-1a cohort remained significantly more adherent than did the GA cohort over subsequent 6-month intervals (7-12 months, 13-18 months), although the significance in differences between their IM-IFN $\beta-1 \mathrm{a}$ and IFNB-1 $\beta$ or SC-IFN $\beta$-1a cohorts varied. ${ }^{28}$

Our findings of no significant differences in persistence between the IM-IFN $\beta$-1a cohort and the other cohorts are largely consistent with Reynolds et al, ${ }^{28}$ who found no difference in regression-adjusted persistence between the IM-IFN $\beta$-1a cohort and the SC-IFN $\beta$-1a and GA cohorts. In contrast to our study, Reynolds observed that patients in the IFN $\beta$-1b cohort were more likely than those in the IM-IFN $\beta$-1a cohort to have a minimum 90-day gap in therapy and were less likely to be on IFN $\beta-1 b$ at each 6-month interval.

The significantly higher odds of adherence in the IM-IFN $\beta-1$ a cohort compared with the IFN $\beta-1 b$,
SC-IFN $\beta$-1a and GA cohorts could be partly attributable to a more convenient dosing schedule, once weekly for IM-IFN $\beta$-1a compared with multiple times weekly for IFN $\beta-1 b$ and SC-IFN $\beta-1 a$ and daily for GA. In addition to convenience, the weekly injection schedule for IM-IFN $\beta$-1a may also help allay patients' fear of injection. More favorable adherence in the IM-IFN $\beta$-1a cohort could also be a function of higher perceived efficacy insofar as IM-IFN $\beta$-1a is indicated both to decrease the rate of relapses and to slow the progression of disability in RRMS. Research examining reasons for lack of adherence to DMT has shown that MS patients are more likely to be adherent when the dosing schedules are relatively convenient, when there are fewer side effects (eg, injection site reactions, flu-like symptoms, injection pain), and when patients perceive that their DMTs are beneficial. ${ }^{14,15,32,33}$ The lack of a significant difference in adherence between the IM-IFN $\beta$-1a and SC-IFN $\beta$-1a cohorts for subjects who initiated DMT therapy when SC-IFN $\beta$-1 a was available could be attributable to a "halo" effect with the newness of SC-IFN $\beta$-1a; that is, MS patients and their providers might reasonably have been excited by the arrival of a new MS therapy and more likely to use it in an adherent manner.

Multiple studies have demonstrated the clinical, economic, and humanistic benefits of DMT adherence. Adherence to DMTs has been associated with fewer relapses, ${ }^{13,34}$ as well as with less health care resource use and lower costs. DMT adherence has also been found to be inversely related to MSrelated ER visits and hospitalizations. ${ }^{13,35}$ And, importantly, studies have found that MS patients who are adherent to their DMTs tend to report higher quality of life on such dimensions as emotional health, pain, energy, and social function, and fewer neurological deficits. ${ }^{14,15}$

Our results indicate that patient adherence to DMTs could be improved. Side effects and relapses tend to be more prevalent early in DMT treatment and diminish over time, making the first year of treatment a critical time period. Management strategies such as dose titration, concomitant prophylactic therapy (eg, nonsteroidal anti-inflammatory drugs), use of autoinjectors, patient education on rotation of injection sites and safe and effective injection strategies, and management of patient expectations regarding likely side effects could help improve tolerability early in the treatment regimen and in turn help improve patient adherence with therapy. ${ }^{33,36}$ MS patient support programs sponsored by DMT manufacturers (eg, Avonex ${ }^{\circledR}$ Nurse Services and Therapy Support program for IM-IFN $\beta$-1a users, ${ }^{37}$ Shared Solutions ${ }^{\circledR}$ for GA users, ${ }^{38}$ MS LifeLines ${ }^{\circledR}$ 
for SC-IFN $\beta$-1a users, ${ }^{39}$ and BETAPLUS ${ }^{\circledR}$ for IFN $\beta$ - $1 \mathrm{~b}$ users $^{40}$ ) and specialty care management programs provided by health plans ${ }^{35}$ can improve adherence to DMTs. A specialty managed care program offered in 2005 by one large insurer to nearly 4,000 commercial health plan enrollees with MS consisted of mailings of medication and diseasespecific patient education materials, assessment telephone calls by nurses when patients first received medication, periodic follow-up calls, and refill reminder calls.$^{35}$ Results of an evaluation of this program suggested that the program had a positive impact on patient adherence and persistence as well as on hospitalization rates..$^{35}$ Additionally, a series of articles from a summit of multidisciplinary healthcare providers (neurologists, nurses, nurse practitioners, and psychologists) in 2009 $9^{41-44}$ emphasized the importance of the healthcare provider-patient relationship and how nursing interventions, including motivational telephone counseling and telephone-based education and training can improve patient adherence by focusing on ways to combat the most common reasons for DMT discontinuation such as fear of injection, side-effects of the medication, cognitive impairment, and self-efficacy. ${ }^{43}$

\section{Limitations}

Claims database studies facilitate the assessment of realworld treatment patterns and drug-taking behavior. One strength of our analysis derives from a large, geographically diverse study population. Nevertheless, all retrospective database analyses are subject to certain limitations and the results of this study must be interpreted with appropriate consideration of these limitations. Pharmacy claims for filled prescriptions do not necessarily indicate that the medications were injected as prescribed. As previously noted, however, the high MPR suggests that patients were using their DMTs regularly. In addition, diagnosis codes on medical claims may be miscoded or "rule-out" diagnoses. We required both an MS diagnosis and a prescription for or administration of a DMT; this mitigates concerns regarding misclassification of MS patients in the study population. Claims data are constrained by coverage limitations, which determine the data available and limit the generalizability of results to patients enrolled in similar managed care plans.

The most significant limitation specific to this study is the important unobserved and unmeasured factors that likely affect adherence and persistence in individuals with MS. We were unable to observe clinical markers or time since the onset or diagnosis of MS, which could provide insight into the progression and severity of patients' MS. We measured some proxies of MS severity, such as baseline corticosteroid use, but we did not have access to other important clinical measures, such as disease severity or cognitive function. Moreover, we also did not have information on patients' socioeconomic status, participation in therapy support programs, or the availability of family or friends to assist with medication administration. A second study limitation was the selection of new DMT users; patients with any baseline DMT use were excluded from the study population to focus on patients who were initiating DMTs. The 6-month baseline period was selected, in part, to maximize the study population size while allowing for sufficient time to measure covariates. It is possible that some patients in the study population used DMTs prior to the beginning of their baseline periods. We believe, however, that even in such cases, the patients would have been off their DMTs for long enough that they would be considered "naïve" DMT users, if not entirely new users.

\section{Conclusion}

Appropriate and persistent use of DMTs is critical for patients to achieve the full therapeutic value. Our study found that adherence rates varied among DMTs. Patients on IM-IFN $\beta$-1a had significantly higher odds of adherence than did patients on GA, SC-IFN $\beta-1 a$, or IFN $\beta-1 b$. Patient benefits of adherence may include better quality of life, lower risk of relapse, fewer hospitalizations, and fewer ER visits. These benefits may also extend to the health care system as reduced cost due to fewer MS-related hospitalizations and ER visits. Additional studies are needed to better understand the clinical and economic implications of poor adherence and to develop strategies to improve patient adherence and persistence.

\section{Acknowledgments/disclosure}

Support for this study was provided by Biogen Idec. Dr. Agarwal and Ms. Dembek are employees of Biogen Idec. Dr. Halpern and Ms. Borton are employees of i3 Innovus, which was contracted by Biogen Idec to conduct the study. Dr. Lopez-Bresnahan is an employee of i3 Research. Kathy Oneacre provided assistance with medical writing of the manuscript and is an employee of i3 Innovus. Amy O'Donnell, MD, and Tomislav Babic, MD of i3 Research reviewed this manuscript and provided clinical input. Preliminary findings from this study were presented at the 
American Academy of Neurology 62nd Annual Meeting, April 2010, Toronto, Canada and the 2010 Annual Meeting of the Consortium of Multiple Sclerosis Centers, June 2010 , San Antonio, TX, USA.

\section{References}

1. Compston A, Coles A. Multiple sclerosis. Lancet. 2002;359(9313): 1221-1231.

2. Rolak LA. Multiple sclerosis: it's not the disease you thought it was. Clin Med Res. 2003;1(1):57-60.

3. National Multiple Sclerosis Society. Just the facts (2008-2009). Available from: http://www.nationalmssociety.org/about-multiplesclerosis/what-we-know-about-ms/what-is-ms/index.aspx. Accessed Dec 82010.

4. Bainbridge JL, Rieckmann P. Multiple sclerosis. In: DiPiro JT, Talbert R, Yee G, Matzke G, editors. Pharmacotherapy: a pathophysiologic approach. New York: McGraw-Hill Medical; 2008. p. 913-926.

5. Ropper AH, Samuels MA. Multiple sclerosis and allied demyelinating diseases. Adams and Victor's principles of neurology. 9th ed. New York: McGraw-Hill Medical; 2009:771-796.

6. IFNB Multiple Sclerosis Group. Interferon beta-1b is effective in relapsing-remitting multiple sclerosis. I. Clinical results of a multicenter, randomized, double-blind, placebo-controlled trial. The IFNB Multiple Sclerosis Study Group. Neurology. 1993;43(4): 655-661.

7. Jacobs LD, Cookfair DL, Rudick RA, et al. Intramuscular interferon beta-1a for disease progression in relapsing multiple sclerosis. The Multiple Sclerosis Collaborative Research Group (MSCRG). Ann Neurol. 1996;39(3):285-294.

8. Johnson KP, Brooks BR, Ford CC, et al. Sustained clinical benefits of glatiramer acetate in relapsing multiple sclerosis patients observed for 6 years. Copolymer 1 Multiple Sclerosis Study Group. Mult Scler. 2000;6(4):255-266.

9. PRISMS. Randomised double-blind placebo-controlled study of interferon beta-1a in relapsing/remitting multiple sclerosis. PRISMS (Prevention of Relapses and Disability by Interferon beta-1a Subcutaneously in Multiple Sclerosis) Study Group. Lancet. 1998; 352(9139):1498-1504.

10. World Health Organization. Adherence to long-term therapies: Evidence for action. Available from: http://www.who.int/chp/knowledge/ publications/adherence_full_report.pdf. Accessed Dec 82010.

11. New England Health Care Institute. Thinking outside the pillbox: A system-wide approach to improving patient medication adherence for chronic disease. Available from: http://www.nehi.net/publications/ 44/thinking_outside_the_pillbox_a_systemwide_approach_to_ improving_patient_medication_adherence_for_chronic_disease. Accessed Dec 82010.

12. Cramer JA, Roy A, Burrell A, et al. Medication compliance and persistence: terminology and definitions. Value Health. 2008;11(1): 44-47.

13. Steinberg SC, Faris RJ, Chang CF, Chan A, Tankersley MA. Impact of adherence to interferons in the treatment of multiple sclerosis: a nonexperimental, retrospective, cohort study. Clin Drug Investig. 2010; 30(2):89-100.

14. Treadaway K, Cutter G, Salter A, et al. Factors that influence adherence with disease-modifying therapy in MS. $J$ Neurol. 2009; 256(4):568-576.

15. Devonshire V, Lapierre Y, Macdonell R, et al. The Global Adherence Project (GAP): a multicenter observational study on adherence to disease-modifying therapies in patients with relapsing-remitting multiple sclerosis. Eur J Neurol. 2010 Jun 14. [Epub ahead of print].

16. Andrade SE, Kahler KH, Frech F, Chan KA. Methods for evaluation of medication adherence and persistence using automated databases. Pharmacoepidemiol Drug Saf. 2006;15(8):565-574.
17. Tremlett $\mathrm{H}$, van $\mathrm{dMI}$, Pittas F, et al. Adherence to the immunomodulatory drugs for multiple sclerosis: contrasting factors affect stopping drug and missing doses. Pharmacoepidemiol Drug Saf. 2008;17(6): $565-576$.

18. Haynes RB, McDonald HP, Garg AX. Helping patients follow prescribed treatment: clinical applications. JAMA. 2002;288(22):2880-2883.

19. Bruce JM, Hancock LM, Lynch SG. Objective adherence monitoring in multiple sclerosis: initial validation and association with self-report. Mult Scler. 2010;16(1):112-120.

20. Tremlett HL, Oger J. Interrupted therapy: stopping and switching of the beta-interferons prescribed for MS. Neurology. 2003;61(4):551-554.

21. Rio J, Porcel J, Tellez N, et al. Factors related with treatment adherence to interferon beta and glatiramer acetate therapy in multiple sclerosis. Mult Scler. 2005;11(3):306-309.

22. Clerico M, Barbero P, Contessa G, Ferrero C, Durelli L. Adherence to interferon-beta treatment and results of therapy switching. J Neurol Sci. 2007;259(1-2):104-108.

23. O'Rourke KE, Hutchinson M. Stopping beta-interferon therapy in multiple sclerosis: an analysis of stopping patterns. Mult Scler. 2005; 11(1):46-50.

24. Quan H, Sundararajan V, Halfon P, et al. Coding algorithms for defining comorbidities in ICD-9-CM and ICD-10 administrative data. Med Care. 2005;43(11):1130-1139.

25. Charlson ME, Pompei P, Ales KL, MacKenzie CR. A new method of classifying prognostic comorbidity in longitudinal studies: development and validation. J Chronic Dis. 1987;40(5):373-383.

26. Deyo RA, Cherkin DC, Ciol MA. Adapting a clinical comorbidity index for use with ICD-9-CM administrative databases. J Clin Epidemiol. 1992;45(6):613-619.

27. Ollendorf DA, Jilinskaia E, Oleen-Burkey M. Clinical and economic impact of glatiramer acetate versus beta interferon therapy among patients with multiple sclerosis in a managed care population. J Managed Care Pharm. 2002;8(6):469-476.

28. Reynolds MW, Stephen R, Seaman C, Rajagopalan K. Persistence and adherence to disease modifying drugs among patients with multiple sclerosis. Curr Med Res Opin. 2010;26(3):663-674.

29. Sikka R, Xia F, Aubert RE. Estimating medication persistency using administrative claims data. Am J Manag Care. 2005;11(7): 449-457.

30. Abdi H. The Bonferonni and Sidak corrections for multiple comparisons. In: Salkind NJ, editor. Encyclopedia of measurement and statistics. Thousand Oaks, CA: SAGE Publications, Inc; 2007:103-107.

31. Allison PD. Survival analysis using $S A S^{\circledR}$. A practical guide. Cary, NC: SAS Institute, Inc; 1995.

32. Portaccio E, Zipoli V, Siracusa G, Sorbi S, Amato MP. Long-term adherence to interferon beta therapy in relapsing-remitting multiple sclerosis. Eur Neurol. 2008;59(3-4):131-135.

33. Patti F. Optimizing the benefit of multiple sclerosis therapy: the importance of treatment adherence. Patient Prefer Adherence. 2010;4:1-9.

34. Phillips AL, Ivanova JI, Bergman RE, Birnbaum HG, Stewart M, Meletiche DM. Impact of medication adherence to disease-modifying drugs on severe relapse, and direct and indirect costs among employees with multiple sclerosis. Toronto, Ontario, Canada 2010.

35. Tan H, Yu J, Tabby D, Devries A, Singer J. Clinical and economic impact of a specialty care management program among patients with multiple sclerosis: a cohort study. Mult Scler. 2010;16(8):956-963.

36. Girouard N, Theoret G. Management strategies for improving the tolerability of interferons in the treatment of multiple sclerosis. Can J Neurosci Nurs. 2008;30(4):18-25.

37. Biogen Idec. Services and support. Avonex patient services. Available from: http://www.avonex.com/service-and-support.xml. Accessed Dec 82010.

38. Teva Pharmaceuticals. Shared solutions. Support, knowledge, answers for patients with MS using COPAXONE (glatiramer acetate injection). Available from: http://www.copaxone.com/supportServices/default. aspx. Accessed Dec 82010. 
39. EMD serono, Inc and Pfizer Inc. MS lifelines. Available from: www. mslifelines.com. Accessed Dec 82010.

40. Bayer Healthcare Pharmaceuticals. Betaplus MS support group. Available from: http://www.betaseron.com/patients/betaplus/about_ betaplus.jsp. Accessed Dec 82010.

41. Smrtka J, Caon C, Saunders C, Becker BL, Baxter N. Enhancing adherence through education. J Neurosci Nurs. 2010;42(5 Suppl):S19-S29.

42. Saunders C, Caon C, Smrtka J, Shoemaker J. Factors that influence adherence and strategies to maintain adherence to injected therapies for patients with multiple sclerosis. J Neurosci Nurs. 2010;42(5 Suppl):S10-S18.
43. Caon C, Saunders C, Smrtka J, Baxter N, Shoemaker J. Injectable disease-modifying therapy for relapsing-remitting multiple sclerosis: a review of adherence data. J Neurosci Nurs. 2010;42(5 Suppl):S5-S9.

44. Caon C, Saunders C, Smrtka J, et al. Introduction: adherence to diseasemodifying therapies-key to optimizing outcomes in relapsing multiple sclerosis. J Neurosci Nurs. 2010;42(5 Suppl):S1-S4.

\section{Publish your work in this journal}

Patient Preference and Adherence is an international, peer-reviewed, open access journal focusing on the growing importance of patient preference and adherence throughout the therapeutic continuum. Patient satisfaction, acceptability, quality of life, compliance, persistence and their role in developing new therapeutic modalities and compounds to optimize clinical outcomes for existing disease states are major areas of interest. This journal has been accepted for indexing on PubMed Central. The manuscript management system is completely online and includes a very quick and fair peer-review system. Visit http://www.dovepress.com/ testimonials.php to read real quotes from published authors. 